\title{
Going beyond the textbook: The need to integrate open access primary literature into the Chemistry curriculum
}

\author{
Harry E Pence ${ }^{1 *}$ and Barbara Losoff ${ }^{2}$
}

\begin{abstract}
Unrestricted, open access to scholarly scientific literature provides an opportunity for chemistry educators to go beyond the textbook, introducing students to the real work of scientists. Despite the best efforts of textbook authors to provide information about recent research results, textbooks are not a substitute for learning to use the primary literature. Chemical educators can use open access articles to develop research-related skills, to foster curiosity, and to cultivate the next generation of scientists. It is becoming increasingly important for chemical educators to teach undergraduates how online journals are changing the nature of chemical research. Some institutions can not afford online subscription costs, and open access journals can be an important resource to provide practical experience. Open access publications eliminate the barriers to the central work of scientists providing chemistry educators (whether at well-endowed or economically limited colleges) with the key resources for enhancing student learning through current, relevant research.
\end{abstract}

\section{Introduction}

The nature of the chemical literature is changing more rapidly now than probably at any previous time in history. Online publication facilitates many other changes that are more profound than simply finding chemical information on the World Wide Web (WWW). Timesaving features, such as rapid online search, hyperlinks to related material (including supplementary data files), embedded videos, and RSS (Really Simple Syndication) feeds are already becoming common, but even more dramatic changes may soon become a reality. Elsevier's Article of the Future Project is already using the latest visualization techniques and integrated multimedia, as well as allowing readers the ability to access an article at different points, moving through the article focusing on only the sections of interest [1].

The development of open access scientific journals is a major change in scholarly communication that has been triggered by online publications. Willinsky has suggested ten different definitions for open access [2]. This article will focus on open access to mean free, online access to

\footnotetext{
* Correspondence: pencehe@oneonta.edu

'Department of Chemistry and Biochemistry, SUNY at Oneonta, New York, 13820, USA

Full list of author information is available at the end of the article
}

articles or journals as soon as they are published. Open access publishing has become a touchstone for change in scientific scholarly communications sparking debate over impact factors, peer-review, public access, cost, and copyright. However, largely missing from the discussion is the more immediate impact of these changes on chemical education. Open access scholarly literature provides an opportunity for all educators to teach their students how to read and use peer-reviewed papers while enriching the chemistry curriculum with current, relevant research.

A 2005 report entitled, "Are Chemical Journals Too Expensive and Inaccessible?" notes that, "Small universities and undergraduate institutions may have problems accessing some journals, whereas larger universities with bigger budgets appear to have enough access [3]." Recent economic problems may well have exacerbated this problem for many colleges [4]. This suggests that some institutions may lack the access that their students need to learn how to use the modern chemical literature. Despite the best efforts of textbook authors to provide information about recent research results, textbooks are not a substitute for learning to use the primary literature. Fister points out that the current economic problems have left some 
scholars without access to the literature because they are unemployed [5].

\section{Open Access Publications}

Open access journals provide free, online access to research articles for any user. The open access movement became widely recognized after the Budapest Open Access Initiative of 2001 [6]. This initiative, sponsored by the Open Access Society, was an international effort to make research from all disciplines freely available on the Internet, and this position has since developed considerable support. The essential characteristic of open access journals is that they are not paid for by subscribers and that the journals are usually funded by a combination of grant support or payments by authors.

The current impetus spurring open access publishing comes from the funding agencies themselves, as increasingly both governments and private institutions have mandated open access requirements for funded research. In the United States, the U.S. Congress passed the National Institutes of Health (NIH) Public Access Policy of 2008 which required that federally funded research be made available at no cost to the taxpayer through PubMed Central, reaching the public domain within twelve months after publication [7]. Private foundations in the US and abroad have been at the forefront ensuring public access to their funded research including the Howard Hughes Medical Institute (HHMI) in the US, the Wellcome Trust in the UK, and the Max Planck Institute in Germany. Other open access pronouncements include the Berlin Declaration with affiliates from 55 countries [8], and the Brisbane Declaration from Australia representing numerous constituencies and countries [9].

\section{Open Access in Chemistry Research}

Although the primary chemistry literature is not nearly as 'open' as biology or medicine, there are open access peer-reviewed publications of significance to chemical educators. According to the Directory of Open Access Journals, there are more than 6270 open access publications available online as of this date, of which over 200 titles are related to chemistry or chemical engineering [10]. Todd has discussed the status of open access and open source in Chemistry as of 2007 but did not mention the possible impact on chemical education [11].

The largest free digital archive of the biomedical and life sciences scholarly literature is PubMed Central which is operated by the U.S. National Library of Medicine under the direction of the NIH [12]. PubMed Central has more than 2 million peer-reviewed articles. This repository will continue to grow as a result of the NIH mandate that publically funded research must be made freely available to the public.
BioMed Central, a London-based open access publisher has over 200 full-text journals that include: chemical biology, biotechnology, biochemistry, genetics, pharmacology, and molecular biology [13]. Titles of particular importance to chemistry educators include the Chemistry Central Journal [14], the Journal of Cheminformatics [15] and the Journal of Systems Chemistry [16], all peer-reviewed, open access publications. The Public Library of Science (PLoS), a non-profit organization of scientists committed to "making the world's scientific research a public resource," [17], publishes seven online scholarly journals that are freely available including: PLoS Biology, PLoS Medicine, and PLoS ONE.

The Royal Society of Chemistry (RSC) was one of the first chemical society publishers to offer free or low cost archival journal access to developing countries [18]. The RSC also publishes an open access journal in chemical education, Chemistry Education Research and Practice [19]. In 2006, The American Chemical Society began to offer authors the option of paying to have free online access to their articles on the society's website and also to place their sponsored articles on personal websites and institutional repositories [20]. The Beilstein-Institut publishes open-access journals, such as the Beilstein Journal of Organic Chemistry and Beilstein Journal of Nanotechnology [21].

Educators also have the option of searching Google Scholar, the free search tool for mining the scholarly Web [22]. Google Scholar searches articles, theses, and books from academic publishers, universities and professional societies with links to open access articles as well as those that are pay-per-view.

Several major U.S. universities, including Massachusetts Institute of Technology, Cornell University, Harvard University, Columbia University, and the University of California at Berkeley, are supporting the Compact for Open Access Publishing Equity, or COPE, which provides funds to subsidize the publication fees charged by some open-access journals. Despite this support, few faculty researchers seem willing to participate in this program [23]. As noted in the previous paragraph, there are a number of well-know journals that will accept open access papers, so it seems unlikely that this resistance arises from a desire to publish in more prestigious journals. Apparently, many faculty are either unaware of the possibilities inherent in open access or else are too busy to do the necessary paperwork to receive the support. If colleges talked more freely about open access publications, it might well make more colleagues aware that this was a viable option.

\section{Using Primary Literature in the Classroom}

Various science educators have demonstrated the benefits of integrating primary literature into the undergraduate 
curriculum [24]. In fact, funding agencies, such as the NSF and the Howard Hughes Medical Institute, increasingly offer support for educators developing science curricula that incorporates research-like experiences into undergraduate teaching [24]. In a recent article in the Journal of Chemical Education, Jensen et al reference a number of articles that describe ways to introduce undergraduate chemistry students to the primary literature [25]. Jensen et al argue that a course in the chemical literature is not enough. Undergraduate students should be taught how to evaluate, interpret, and incorporate chemical literature when communicating as a component of individual upper-level chemistry courses. The authors of this paper agree with Jensen et al but also feel that peer-reviewed papers from open access publications can expand the potential for enriching scientific education.

A number of innovative higher-level learning methodologies have been developed to expose science undergraduates to the primary literature. Pence and Pence have described the use of Real Simple Syndication (RSS) [26] and social tagging for teaching chemistry [27], and although the available open access resources may be less extensive than those used in these projects, it is likely that these methods could be adapted to the open access literature. These programs can be adapted by chemistry educators for integrating open access scholarly articles into the chemistry curriculum at the college and even the secondary level. The adaptation of primary literature through active learning modules provides students with:

- a proficiency in both reading and evaluating research literature

- an ability to develop scientific reasoning and critical thinking skills

- an ability to participate in both the scientific process and discourse

Another model developed in order to guide undergraduates in their analyses of primary journal articles offered a step by step methodology: Consider, Read, Elucidate hypotheses, Analyze and interpret the data, and Think of the next Experiment (CREATE). In the CREATTE model the articles were selected based on the research conducted in a single laboratory over a period of years, allowing an "in-depth study of a single line of scientific research [28]." Students were asked to track the evolution of scientific ideas generated through the research papers. An assessment of CREATE found that students improved their "ability to read and critically analyze scientific data, as well as their understanding of, and interest in, research and researchers [28]." An additional outcome found that the "CREATE approach demystified the process of reading a scientific article [28]."

\section{Open Access and Chemistry Education}

As noted previously, there are a number of instructional models for teaching using the primary literature, and there is general agreement that this topic is important in the undergraduate curriculum. It has also been noted that many small colleges and most high schools find it to be increasingly difficult to afford to subscribe to conventional online chemistry journals. The obvious solution is to use open access chemistry journals, since they are free and widely available for anyone with access to the World Wide Web.

Malcolm Campbell, an advocate for taking advantage of open access publications in education, reminded educators that "research begins in the literature, not in the laboratory," and that "the benefit of open-access literature is both obvious and immediate [29]." Chemistry educators have an opportunity to use open access literature to enhance the undergraduate curriculum by incorporating critical evaluations of research methodologies and results. Students working with real problems from current literature can be encouraged to ask new questions and to design their own experiments.

The organization Chemists Without Borders has asserted that "open access is necessary to the development of equitable access to chemistry education and research opportunities in both the developed and developing worlds [30]." Free, unrestricted access to chemistry research provides an opportunity for all students to explore and assess the research regardless of their institutional resources. Although textbooks provide the foundation, it is the primary research where chemistry "comes alive with many unanswered and controversial issues, which are keys to stimulating students' curiosity and motivating them to learn [31]."

Open access publications provide ease of use for educators themselves by allowing unlimited access to published works without copyright concerns, subscription fees or limited downloads. Open access research articles provide an opportunity for chemistry educators to stay current in their field and to incorporate cutting-edge research into their curriculum.

\section{Conclusion}

Open access peer-reviewed journals provide the means for chemistry educators, regardless of institutional resources, to introduce undergraduate students to the primary literature and to promote higher level cognitive skills by integrating primary scientific literature into the curriculum. As a result of exposing students to the research articles that are available free of charge, educators can bring chemistry to life, by exploring relevant 
papers that spark curiosity. The integration of open access articles into undergraduate curriculum hold the promise of a deeper understanding of both chemistry and science.

The authors agree with Thomas Cech, Nobel Laureate in Chemistry, who argued that the future of the world is at stake regarding the dual need for both scientists and a scientifically educated citizenry [32]. Open access publications eliminate the barriers to the central work of scientists providing chemistry educators (whether at rich or economically limited colleges) with the key resources for enhancing student learning through current, relevant research. Integrating open access publications into the curriculum, offers students "equal access to a growing portion of the literature that Nobel laureates and investigators at wealthy institutions enjoy [29]." Open access scholarly articles provide chemistry educators with free, 'reliable resources' for supplementing the textbook in order to improve student research skills, kindle their interest in chemistry, and concomitantly educate both future scientist and citizen.

\section{Author details \\ 'Department of Chemistry and Biochemistry, SUNY at Oneonta, New York, 13820, USA. ${ }^{2}$ Science Library, University of Colorado at Boulder, CO, 80309, USA}

Received: 13 January 2011 Accepted: 6 April 2011

Published: 6 April 2011

\section{References}

1. Schemm Y: Elsevier announces the "Article of the Future". Elsevier; 2009 [http://www.elsevier.com/wps/find/authored_newsitem.cws_home/ companynews05_01279].

2. Willinsky J: The access principle: The case for open access to research and scholarship The MIT Press, Cambridge, MA; 2006, 212-13.

3. National Research Council (US) Chemical Sciences Roundtable, Heindel ND, Masciangioli TM, von Schaper E, editors: Are Chemical Journals Too Expensive and Inaccessible?: A Workshop Summary to the Chemical Sciences Roundtable. Washington (DC): National Academies Press (US); 2005, 18.

4. Scudellari M: Library cuts threaten research. TheScientist 2010 [http://www. the-scientist.com/news/display/57728/].

5. Fister B: The great disconnect: Scholars without libraries. Inside Higher Education 2010 [http://www.insidehighered.com/blogs/library_babel_fish/ the_great_disconnect_scholars_without_libraries].

6. Budapest Open Access Initiative. [http://www.soros.org/openaccess/]

7. National Institutes of Health. [http://publicaccess.nih.gov/].

8. Berlin Declaration on Open Access. [http://www.zim.mpg.de/openaccessberlin/berlin_declaration.pdf].

9. Suber PL: Open Access News. 2008 [http://www.earlham.edu/ peters/fos/ 2008/10/brisbane-declaration-on-oa.html].

10. Directory of Open Access Journals. [http://www.doaj.org/]

11. Todd MH: Open access and open source in Chemistry. Chem Cent J 2007, 1:3.

12. PubMed Central. [http://www.ncbinlm.nih.gov/pmc/].

13. BioMed Central. [http://www.biomedcentral.com/browse/journals/].

14. Chemistry Central Journal. [http://www.journal.chemistrycentral.com/].

15. Journal of Cheminformatics. [http://www.jcheminf.com/].

16. Journal of Systems Chemistry. [http://www.jsystchem.com/].

17. Public Library of Science. [http://www.plos.org/].

18. Royal Society of Chemistry. [http://www.rsc.org/Publishing/Journals/ DigitalArchive/Index.asp].
19. Chemistry Education Research and Practice. 2010 [http://pubs.rsc.org/en/ Journals/Journallssues/RP\#/

issuelD=RP01 1004\&Type=Current\&issnprint=1756-1108].

20. Rovner S: ACS offers open-access option to authors. Chem Eng News 2006, 84(36):11.

21. Thayer A: Open-access organic chemistry journal debuts. Chem Eng News 2005, 83(12):13.

22. Google Scholar. [http://scholar.google.com/].

23. Kolowich S: Long road to open access. Inside Higher Education 2010 [http://www.insidehighered.com/news/2010/10/11/cope].

24. DebBurman SK: Learning how scientists work: experimental research projects to promote cell biology learning and scientific process skills. Cell Bio Ed 2002, 1:154-172.

25. Jensen D, Narske R, Ghinazzi C: Beyond chemical literature: Developing skills for chemical research literacy. J Chem Ed 2010, 87(7):700-2.

26. Pence $L E$, Pence HE: Accessing and managing scientific literature: Using RSS in the classroom. J Chem Ed 2008, 85(10):1449-52.

27. Pence $L E$, Pence $H E$ : Assessing resource bias and engaging students to personalize class content through Internet social tagging. J Chem Ed 2009, 86(1):41-44.

28. Wu J: Linking assessment questions to a research article to stimulate self-directed learning and develop high-order cognitive skills in an undergraduate module of molecular genetics. CBE Life Sciences Education 2009, 8:283-290.

29. Campbell AM: Open access: A PLoS for education. PLoS Biology 2004 2:560-563.

30. Chemists Without Borders. [http://www.chemistswithoutborders.org/about. html].

31. Gilbert JK, Justi R, Van Driel JH, De Jong O, Treagust DF: Securing a future for chemical education. Chem Ed Res Prac 2004, 5:5-14.

32. Cech T, Kennedy D: Doing more for Kate. Science (Washington, D.C) 2005, 310:1741.

doi:10.1186/1752-153X-5-18

Cite this article as: Pence and Losoff: Going beyond the textbook: The need to integrate open access primary literature into the Chemistry curriculum. Chemistry Central Journal 2011 5:18.

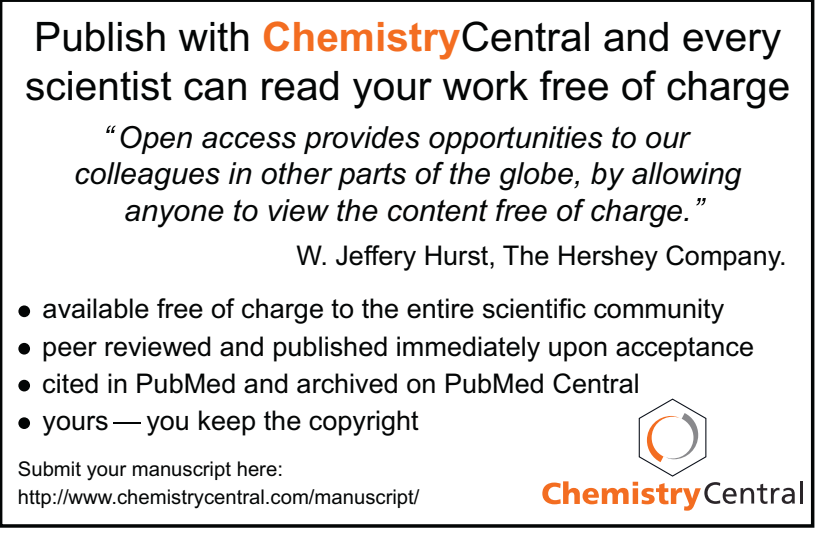

